\title{
ERCP başarısı ve komplikasyonlarının yaşa göre değerlendirilmesi
}

\author{
Evaluation of endoscopic retrograde cholangiopancreatography success and complications according \\ to age
}

(D) Zehra Betül PAKÖZ1 ${ }^{1}$ (D) Süleyman GÜNAY², (D) Sevil ÖZER SARI ${ }^{1}$

Tepecik Eğitim ve Araştırma Hastanesi, ${ }^{1}$ Gasteroenteroloji Kliniği, Izmir

Katip Çelebi Üniversitesi, Atatürk Eğitim ve Araştırma Hastanesi, ${ }^{2}$ Gastroenteroloji Kliniği, Izmir

\begin{abstract}
Giriş ve Amaç: Endoskopik retrograd kolanjiopankreatografi diğer gastrointestinal endoskopik yöntemlere göre daha yüksek komplikasyon oranına sahiptir. Özellikle komplikasyon gelişstiğinde, yaşlı hastaların operasyonlar sonrası düzelmesi gençlere göre daha zor olmaktadır. Bu çalışmada amacımız çeşitli yaş gruplarında yapılan endoskopik retrograd kolanjiopankreatografi işlemlerinin değerlendirilmesi ve yaşlı hastalarda işlem başarısı ve güvenilirliğinin değerlendirilmesidir. Gereç ve Yöntem: Kliniğimizde Ocak 2018-Haziran 2018 tarihleri arasinda yapilan 301 hastaya ait endoskopik retrograd kolanjiopankreatografi işlemleri retrospektif olarak değerlendirildi. Hastalar yaşlarına göre 60 yaş altı, 60-80 yaş arası ve 80 yaş üstü olarak 3 gruba ayrıldı. Her grupta işlem başarısı, komplikasyonlar, işlem tekrarı gerekliliği, işlem endikasyonları değerlendirildi ve gruplar birbiriyle karşılaştırıldı. Bulgular: Hastalarm 163’ü (\%54.2) kadın ve 138’i (\%45.8) erkekti. Tüm hasta gruplarında en sik endoskopik retrograd kolanjiopankreatografi endikasyonu safra taşıdı. Ișlem bașarısı, işlem tekran gerekliliği, pre-cut kesi gerekliği açısından gruplar arası fark saptanmadı. Grup 2 ve 3'de endoskopik retrograd kolanjiopankreatografi endikasyonlarn benzer iken Grup l'de Grup 2 ve Grup 3'e göre benign nedenler anlamlı olarak daha fazla saptandı. Komplikasyonlar değerlendirildiğinde gruplar arasında istatiktiksel olarak anlamlı fark saptanmadı $(p=0.837)$. Hastaların hiçbirinde perforasyon, kanama ya da ölüm görülmedi. Sonuç: Çalsşmamızda endoskopik retrograd kolanjiopankreatografi başarısı, işlem tekrarı gerekliliği ve komplikasyonlar1 tüm yaș gruplannnda benzer saptadık. Calıșmamız ve literatür eșliğinde yaşlllarda endoskopik retrograd kolanjiopankreatografi işleminin gençler ile benzer etkinlik ve güvenlikte olduğunu düşünmekteyiz.
\end{abstract}

Anahtar kelimeler: Endoskopik retrograd kolanjiyopankreatografi, postERCP, komplikasyonlar, yaşlı hastalar

\section{GİRIS}

Endoskopik retrograd kolanjiyopankreatografi (ERCP), biliyer ve pankreatik hastalıkların tanı ve tedavisinde sık kullanılan bir endoskopik yöntemdir. Daha az invaziv yöntemler olan manyetik rezonans ve endosonografi kullanımı sonrası tanısal amaçlı kullanımı azalmakla beraber, rutinde hala tedavi amaçlı kullanımı sıktır (1). Cerrahi tedaviyle kıyaslandığında ERCP daha az invaziv, komplikasyon ve mortalite oranı daha az ve eşit etkili tedavi sağlayan bir yöntemdir (2). Bununla birlikte ERCP diğer gastrointestinal endoskopik yöntemlere göre daha yüksek komplikasyon oranına sahiptir (3). ERCP komplikasyonları kolanjit, pankreatit, perforasyon, kanama ve kardiyorespiratuvar yan etkilerdir (4).

Paköz ZB, Günay S, Sarn Özer S. Evaluation of endoscopic retrograde cholangiopancreatography success and complications according to age. Endoscopy Gastrointestinal 2019;27:89-92.
Background and Aims: Endoscopic retrograde cholangiopancreatography has a higher complication rate than other gastrointestinal endoscopic methods. It is more difficult for elderly patients than for younger patients to recover after surgery, especially when complications occur. This study aimed to evaluate the endoscopic retrograde cholangiopancreatography procedures performed in various age groups and their success and safety in elderly patients. Material and Methods: Endoscopic retrograde cholangiopancreatography procedures performed in 301 patients in our clinic between January 2018 and June 2018 were retrospectively evaluated. The patients were divided into 3 groups according to their age, i.e., <60 years, between 60 and 80 years, and $>80$ years. Procedure success, complications, necessity of reprocedure, and indications were evaluated in each group and the results were compared among the groups. Results: A total of 163 (54.2\%) of the patients were women and 138 (45.8\%) were men. The most common indication for endoscopic retrograde cholangiopancreatography was bile duct in all patient groups. There was no difference among the groups in terms of procedure success, necessity of reprocedure, and pre-cut incision. While the indications for endoscopic retrograde cholangiopancreatography were similar in groups 2 and 3, benign causes were significantly higher in group 1 than in both groups 2 and 3. There was no statistically significant difference among the groups in terms of complications $(p=0.837)$. None of these patients experienced perforation, bleeding, or death. Discussion: We found that endoscopic retrograde cholangiopancreatography success, necessity of reprocedure, and complications were similar among the groups. We conclude that endoscopic retrograde cholangiopancreatography procedure has similar efficacy and safety in elderly patients and younger patients.

Keywords: Endoscopic retrograde cholangiopancreatography, post-ERCP complications, elderly patients

Yaşlı hastalarda safra taşı ya da maligniteye bağlı obstrüksiyonlar ERCP için sık endikasyonlardır. Safra taşlarının prevalansı yaşla birlikte artar. Ayrıca yaşlı hastalarda safra taşına bağlı ERCP gereksinimi giderek artmaktadır (5). Safra taşlanı 70 yaş üstü hastaların neredeyse üçte birinde gelişmektedir (6). Yaşlı hastalarda kanal obstrüksiyonu ile birlikte safra yolu enfeksiyonu gelişme eğilimi vardır. Bunun nedeni, yaşla beraber safra sekresyonunun azalması, safra kesesi kasilma yeteneğindeki azalmaya bağlı retrograd enfeksiyon riskinin artışı ve bozulmuş immün sistemdir (7). Ana kanalda taşı olan hastaların semptomatik olması ve akut kolanjit ve akut pankreatit gibi ciddi komplikasyon riskine sahip olmaları ne-

Illetişim: Zehra Betül PAKÖZ Tepecik Eğitim ve Araştırma Hastanesi, Gastroenteroloji Kliniği, Yenişehir-İzmir Geliș Tarihi: 09.09.2019 Kabul Tarihi: 03.12.2019 
deni ile hızlı ve agresif tedavi gereksinimleri vardır (8). Akut obstrüktif kolanjitte biliyer dekompresyon en önemli tedavi şeklidir ve ERCP ile taşın çıkarılması, nazobiliyer drenaj ya da stent yerleştirilmesi biliyer dekompreasyonu sağlar (9). ERCP'nin 48 saatten daha fazla geciktirilmesi organ hasarları, yoğun bakım gereksinimi ve hatta ölüme neden olabilir (10).

Özellikle komplikasyon geliştiğinde, yaşlı hastaların operasyonlar sonrası düzelmesi gençlere göre daha zor olmaktadır. ERCP'nin en riskli endoskopik yöntem olması nedeni ile yaşlı hastalardaki etkinlik ve güvenilirliğini değerlendiren çalışmalar yapılmıştır. Yaşlı hastalarda ERCP'nin düşük komplikasyon riski ile etkili ve güvenilir bir yöntem olduğu çeşitli çalışmalarda gösterilmiştir (11-13).

Bu çalışmada amacımız çeşitli yaş gruplarında yapılan ERCP işlemlerinin değerlendirilmesi ve yaşlı hastalarda işlem başarısı ve güvenilirliğinin değerlendirilmesidir.

\section{GEREC ve YÖNTEM}

\section{Hastalar}

Kliniğimizde Ocak 2018-Haziran 2018 tarihleri arasında yapilan 301 hastaya ait ERCP işlemleri retrospektif olarak değerlendirildi. ERCP yapılan hastaların demografik bilgileri, işlem endikasyonları, işlem başarısı ve işlem sonrası gelişen komplikasyonlar kaydedildi. Hastalar yaşlarına göre 60 yaş altı, 60-80 yaş arası ve 80 yaş üstü olarak 3 gruba ayrıldı. Her grupta işlem başarısı, komplikasyonlar, işlem tekrarı gerekliliği, işlem endikasyonları değerlendirildi ve gruplar birbiriyle karşılaştırıldı. 18 yaş altı hastalar çalışmaya dahil edilmedi.

\section{Endoskopik Prosedür}

ERCP işlemleri 3. basamak eğitim ve araştırma hastanemiz endoskopi ünitesinde, ERCP için deneyimli 4 hekim tarafından gerçekleştirildi. Tüm işlemler midazolam, fentanyl ve ketamin kullanılarak genel anestezi altında ve monitörize olarak yapıldı. İşlem standart yan görüşlü endoskoplar ile gerçekleştirildi. Hastaların tümünden bilgilendirilmiş onam alındı.

\section{Komplikasyonlar (14)}

Post-ERCP pankreatitis: Yeni gelişen karın ağrısı ile birlikte, işlemden 24 saat sonra serum lipaz ya da amilaz değerlerinde en az 3 kat artış olmasıdır.

Kanama: Işlem sonrası endoskopik venöz sızma ya da hemoglobin seviyesinin en az $3 \mathrm{~g} / \mathrm{dL}$ azalmasıdır.

Perforasyon: Işlem sonrası gelişen ve herhangi bir görüntüleme yöntemi ile saptanan retroperitoneal ya da barsak duvarı perforasyonudur.

Kolanjit: Biliyer nedenler dışında başka bir enfeksiyon kaynağ olmaksızın, ERCP sonrası 24 saatten daha uzun süren 38.1 ve üzeri ateş yüksekliğidir.

\section{İstatistiksel Analiz}

Tüm istatistik analizler SPSS Statistics 24.0 programı ile değerlendirildi. Kategorik değişkenler için gruplar arası karşılaştırma Pearson ki-kare testinin exact yöntemi ile yapıldı. Devamlı değissken verileri ortalama ve standart sapma olarak gösterildi. Endikasyon için Bonferroni düzeltmeli iki oran z testi çoklu karşılaştırma testi kullanıldı. p değerinin 0.05 altında olması istatistiksel olarak anlamlı kabul edildi.

\section{BULGULAR}

Toplam 301 hastaya yapılan ERCP işlemleri değerlendirildi. Hastaların 163'ü (\%54.2) kadın ve 138'i (\%45.8) erkekti. Ortalama yaş 61.8 (18-94) saptandı. Hasta yaşı 60 altında olanlar Grup 1, 60-80 yaş arası olanlar Grup 2 ve 80 yaş üstü olanlar Grup 3 olarak grupland. Grup l'de 135 (\%44.9), Grup 2'de 99 (\%32.9) ve Grup 3'de 67 (\%22.3) hasta mevcuttu. Tüm hasta gruplarında en sık ERCP endikasyonu safra taşıydı. Işlem başarısı, işlem tekrarı gerekliliği, pre-cut kesi gerekliği açısından gruplar arası fark saptanmadı. Hastaların başlangıç karakteristikleri ve ERCP özellikleri Tablo l'de özetlenmiştir.

ERCP endikasyonları malign nedenler ve benign nedenler olarak iki gruba ayrıldı. Grup 2 ve 3'de ERCP endikasyon-

\section{Tablo 1. ERCP yapılan hastaların başlangıç karakteristikleri ve ERCP özellikleri}

$\begin{array}{lcccc} & \text { Grup 1 (n=135) } & \text { Grup 2 (n=99) } & \text { Grup 3 (n=67) } & \text { P } \\ \text { Cinsiyet } & 70(51.9) & 52(52.5) & 41(61.2) & 0.461 \\ \text { Kadın } & 65(48.1) & 47(47.5) & 26(38.3) & \\ \quad \text { Erkek } & 48.1 \pm 13.6 & 73.1 \pm 40 & 85.6 \pm 3.1 & *<0.001 \\ \text { Ortalama yaş (yıl) } & 133(98.5) & 87(88.8) & 56(83.6) & +>0.5 \\ \text { ERCP endikasyonları } & 2(1.5) & 12(12.1) & 11(16.4) & 0.245 \\ \quad \text { Benign nedenler } & 129(95.6) & 98(99.0) & 63(94.0) & 0.471 \\ \quad \text { Malign nedenler } & 10(7.4) & 12(12.1) & 6(9) & 0.390\end{array}$

*Grup l'in Grup 2 ve Grup 3 ile karşılaştırılması. +Grup 2 ve Grup 3 karşılaştırması. 
ları benzer iken Grup l'de Grup 2 ve Grup 3'e göre benign nedenler anlamlı olarak daha fazla saptandı. Tablo 2'de tüm ERCP endikasyonları özetlenmiştir.

Komplikasyonlar değerlendirildiğinde Grup l'de 9 pankreatit-3 kolanjit (\%10.1), Grup 2'de 5 pankreatit-1 kolanjit (\%12), Grup 3'de 4 pankreatit (\%8) ve Grup 4'de 1 pankreatit (\%5) saptandı. İstatiktiksel olarak gruplar arasında fark saptanmadı ( $\mathrm{p}=0.837)$. Hastaların hiçbirinde perforasyon, kanama ya da ölüm görülmedi. Gruplara göre komplikasyonlar Tablo 3'de özetlenmiştir.

\section{TARTISSMA}

ERCP pankreatobiliyer hastalıklarda tedavi amaçlı yaygın olarak kullanılmaktadır. Yaşlılarda eşlik eden hastalıklar ve antitrombotik ajan kullanımı gençlere göre daha fazladır (15-17). Bu nedenle, yaşlilarda gençlere göre cerrahi komplikasyonların ve mortalite oranlarının daha fazla olduğu bilinmektedir (18). Akut kolanjitli yaşlı hastalarda gençlere göre semptomlar daha belirsizdir, eşlik eden hastalıklar daha fazladır, tanı gecikmesi daha sıktır ve hastalar daha şiddetli evrelerde tanı alır. Klasik Charcot triadı bu hastalarda sadece \%4.2 oranında görülür $(16,19)$. Tüm bu nedenler doğrultusunda, bu çalışmamızda ERCP işleminin yaşlılardaki etkinliği ve güvenliğini diğer yaş grupları ile karşılaştırmayı amaçladık.

Çalışmamızda en sık ERCP nedenleri taş ve maligniteye bağlı obstrüksiyonlar olarak saptandı. Altmış yaş altı hastalarda benign nedenler, 60 yaş üstü hastalara göre anlamlı olarak daha fazlaydı. Yaşla birlikte malign nedenlerin arttığı bilinmektedir. Bizim çalışmamızda da 60 yaş üstünde malign nedenler

\begin{tabular}{lc} 
Tablo 2. Hastaların ERCP endikasyonları \\
\hline Endikasyon & n (\%) \\
Taş & $244(80.7)$ \\
Benign darlık & $11(3.6)$ \\
Pankreas ca & $6(2)$ \\
Kist hidatik & $1(0.3)$ \\
Safra kaçağı & $4(1.3)$ \\
Koledok kisti & $2(0.7)$ \\
SOD & $15(5)$ \\
Papilla ca & $7(2.3)$ \\
Kolanjiyo ca & $12(4)$ \\
\hline
\end{tabular}

SOD: Sfinkter Oddi disfonksiyonu anlamlı olarak daha fazla saptandı. Bu sonuç önceki çalışmalarla benzerdi $(15,20,21)$.

Çeşitli nedenlerle yaşlılarda ERCP'nin teknik başarısının genç hastalara göre daha düşük olması beklenebilir. Bu nedenler arasında periampuller divertiküller, büyük ve çok sayıda taş varlığı ve sedasyona bağlı nedenler sayılabilir $(20,22)$. Bununla birlikte, yapılan birçok çalışmada acil durumlarda dahi işlem başarısı ve pre-cut sfinkterotomi ihtiyacı yaşlılarda gençlere göre benzer saptanmıştır $(20,21,24,25,30)$. Biz çalışmamızda, işlem başarısı ve pre-cut sfinkterotomi ihtiyacı aşısindan gruplar arasında anlamlı bir farklılık saptamadık. Bu nedenle, yaşlılarda ERCP teknik başarısının gençlerle benzer olduğunu düşünmekteyiz.

Işlem tekrarı gerekliliği açısından da hasta grupları arasında farklılık saptamadık. Yaşlı hastalarda işlem tekrarı gerekliliğini daha fazla bulan çalışmalar mevcuttur $(15,26)$. Yaşlı hastalarda safra taşlarının daha büyük ve daha çok sayıda olması işlem tekrarını gerektirebilmektedir.

Literatürde 65, 75, 80 ya da 90 yaş üstü hastalarda ERCP güvenliğini değerlendiren çeşitli çalışmalar mevcuttur ve bazı çalışmalarda gençlere göre kıyaslama yapılmıştır. Bu çalışmaların bir kısmında yaşlılarda gençlere göre daha fazla komplikasyon ve mortalite görüldügü bildirilmiştir $(9,24,27,28)$. Birçok diğer çalışmada yaşlı hastalarda komplikasyonlar diğer yaş grupları ile benzer bulunmuştur $(15,16,20,21,25,29$ 31). Tüm erişkin grubunda ERCP ilişkili morbidite \%3.4-8.5 arasında saptanmıştır $(3,16,21,30)$.

ERCP sonrası en sık görülen komplikasyon akut pankreatittir $(15,21)$. Çalışmamızda da en sık saptanan komplikasyon akut pankreatitti. Han ve arkadaşları yaşlılarda gelişen postERCP pankreatitin şiddetinin tüm hastalarda hafif olduğunu görmüşlerdir. Yaşlılarda post-ERCP pankreatit oranlarının gençlere göre daha düşük saptandığı diğer çalışmalarda da bu durumun pankreatik atrofi ve fibrozisle ilişkili olabileceği belirtilmiştir $(20,32)$.

İşlem sonrası kolanjit çalışmamızdaki hastalarda görülen diğer bir komplikasyondu ve diğer çalışmalardaki sonuçlara benzer olarak gruplar arası farklılık saptanmadı (20).

Perforasyon, ölüm ve kanama hiçbir hastada gözlenmedi. Mortalite oranları önceki çalışmalarda \%0-1.6 arasında bildirilmiştir $(12,13,21)$. Park ve arkadaşları, mortalite için en önemli göstergeleri biliyer drenaj zamanlaması ve kolanjitin

Tablo 3. ERCP komplikasyonlarının yaş gruplarına göre değerlendirmesi

$\begin{array}{lcccc} & \text { Grup 1 (n, \%) } & \text { Grup 2 (n, \%) } & \text { Grup 3 (n, \%) } & \text { P } \\ \text { Yok } & 119(88.1) & 89(89.9) & 62(92.5) & \\ \text { Pankreatit } & 13(9.6) & 7(7.1) & 5(7.5) & 0.661 \\ \text { Kolanjit } & 3(2.2) & 3(3.0) & 0(0) & \end{array}$


şiddeti olarak belirlemiş olup, yaş ile mortalite arasında ilişki saptamamışlardır (16). Garcia ve arkadaşları, yaşlı hastalarda antikoagülan kullanımının daha sık olması nedeni ile ERCP ilişkili kanamaların bu hasta grubunda daha sık olduğunu raporlamışlardır (33). Kanama komplikasyonunu genç ve yaşlılarda benzer bulan çalışmalar da mevcuttur $(12,20,34)$. Sonuç olarak, çalışmamızda 60 yaş altı, 60-80 yaş arası ve 80 yaş üstü grupta komplikasyonlar benzer saptandı. Çalışmamız verilerine göre ERCP güvenliği tüm yaş gruplarında benzerdir.

Çalışmamızın bazı kısıtlılıkları vardır. İlk olarak çalışma retrospektif bir çalışmadır. Ayrıca komplikasyon olarak sadece ERCP ile direkt ilişkili komplikasyonlar değerlendirmeye

\section{KAYNAK}

1. Mazen Jamal M, Yoon EJ, Saadi A, Sy TY, Hashemzadeh M. Trends in the utilization of endoscopic retrograde cholangiopancreatography (ERCP) in the United States. Am J Gastroenterol 2007;102:966-75.

2. Dalton HR, Chapman RW. Role of biliary stenting in the management of bile duct stones in the elderly. Gut 1995;36:485-7.

3. Andriulli A, Loperfido S, Napolitano G, et al. Incidence rates of post-ERCP complications: a systematic survey of prospective studies. Am J Gastroenterol 2007;102:1781-8.

4. ASGE Standards of Practice Committee, Anderson MA, Fisher L, Jain R, et al. Complications of ERCP. Gastrointest Endosc 2012;75:467-73.

5. Siegel JH, Kasmin FE. Biliary tract diseases in the elderly: management and outcomes. Gut. 1997;41:433-5.

6. Tierney S, Lillemoe KD, Pitt HA. The current management of common duct stones. Adv Surg 1995;28:271-99.

7. Provinciali M, Smorlesi A. Immunoprevention and immunotherapy of cancer in ageing. Cancer Immunol Immunother 2005;54:93-106.

8. Roy A, Martin D. Complicated bile duct stones. BMJ Case Rep 2013;2013:bcr201300667.

9. Rahman SH, Larvin M, McMahon MJ, Thompson D. Clinical presentation and delayed treatment of cholangitis in older people. Dig Dis Sci 2005;50:2207-10.

10. Lee F, Ohanian E, Rheem J, et al. Delayed endoscopic retrograde cholangiopancreatography is associated with persistent organ failure in hospitalised patients with acute cholangitis. Aliment Pharmacol Ther 2015;42:212-20.

11. Riphaus A, Stergiou N, Wehrmann T. ERCP in octogenerians: a safe and efficient investigation. Age Ageing 2008;37:595-9.

12. Fritz E, Kirchgatterer A, Hubner D, et al. ERCP is safe and effective in patients 80 years of age and older compared with younger patients. Gastrointest Endosc 2006;64:899-905.

13. Katsinelos P, Kountouras J, Chatzimavroudis G, et al. Outpatient therapeutic endoscopic retrograde cholangiopancreatography is safe in patients aged 80 years and older. Endoscopy 2011;43:128-33.

14. Freeman ML, Nelson DB, Sherman S, et al. Complications of endoscopic biliary sphincterotomy. N Engl J Med 1996;335:909-18.

15. Han SJ, Lee TH, Kang BI et al. Efficacy and safety of therapeutic endoscopic retrograde cholangiopancreatography in the elderly over 80 years. Dig Dis Sci 2016;61:2094-101.

16. Park CS, Jeong HS, Kim KB, et al. Urgent ERCP for acute cholangitis reduces mortality and hospital stay in elderly and very elderly patients. Hepatobiliary Pancreat Dis Int 2016;15:619-25.

17. Kim JE, Cha BH, Lee SH, et al. Safety and efficacy of endoscopic retrograde cholangiopan $\neg$ creatograpy in very elderly patients. Korean J Gastroenterol 2011;57:237-42.

18. Cotton PB. Endoscopic management of bile duct stones; (apples and oranges). Gut 1984;25:587-97. alınmıştır. Anestezi ile ilişkili komplikasyonlar da değerlendirmeye alınabilirdi. Hasta sayısının daha çok olması da daha güçlü bir istatistiksel veri sağlayabilirdi.

Sonuç olarak, çalışmamızda ERCP başarısı, işlem tekranı gerekliliği ve komplikasyonları tüm yaş gruplarında benzer saptadık. Çalışmamız ve literatür eşliğinde yaşlılarda ERCP işleminin gençler ile benzer etkinlik ve güvenlikte olduğunu düşünmekteyiz. Her hasta için olası fayda ve riskler gözden geçirilmeli ve ERCP ihtiyacı yaştan bağımsız olarak değerlendirilmelidir. Endikasyonu olan hastalarda ve deneyimli bir endoskopist tarafından yapıldığında ERCP 80 yaş üstü de dahil olmak üzere tüm hasta gruplarında güvenli ve etkili bir tedavi yöntemidir.

19. Agarwal N, Sharma BC, Sarin SK. Endoscopic management of acute cholangitis in elderly patients. World J Gastroenterol 2006;12:6551-5.

20. Tohda G, Ohtani M, Dochin M. Efficacy and safety of emergency endoscopic retrograde cholangiopancreatography for acute cholangitis in the elderly. World J Gastroenterol 2016;22:8382-8.

21. Ukkonen M, Siiki A, Antila A, et al. Safety and efficacy of acute endoscopic retrograde cholangiopancreatography in the elderly. Dig Dis Sci 2016;61:3302-8

22. Zippi M, Traversa G, Pica R, et al. Efficacy and safety of endoscopic retrograde cholangiopancreatography (ERCP) performed in patients with periampullary duodenal diverticula (PAD). Clin Ter 2014;165:e291-4.

23. Yun DY, Han J, Oh JS, et al. Is endoscopic retrograde cholangiopancreatography safe in patients 90 years of age and older? Gut Liver 2014;8:552-6.

24. Takahashi K, Tsuyuguchi T, Sugiyama H, et al. Risk factors of adverse events in endoscopic retrograde cholangiopancreatography for patients aged $\geq 85$ years. Geriatr Gerontol Int 2018;18:1038-45.

25. Saito H, Koga T, Sakaguchi M, et al. Safety and efficacy of endoscopic removal of common bile duct stones in elderly patients $\geq 90$ years of age. Intern Med 2019;58:2125-32.

26. Obana T, Fujita N, Noda Y, et al. Efficacy and safety of therapeutic ERCP for the elderly with choledocholithiasis: comparison with younger patients. Intern Med 2010;49:1935-41

27. Nishikawa T, Tsuyuguchi T, Sakai Y, et al. Old age is associated with increased severity of complications in endoscopic biliary stone removal. Dig Endosc 2014;26:569-76.

28. Pang YY, Chun YA. Predictors for emergency biliary decom $\neg$ pression in acute cholangitis. Eur J Gastroenterol Hepatol 2006;18:727-31.

29. Cotton PB, Lehman G, Vennes J, et al. Endoscopic sphincterotomy complications and their management: an attempt at consensus. Gastrointest En $\neg$ dosc 1991;37:383-93.

30. Garcia CJ, Lopez OA, Islam S, et al. Endoscopic retrograde cholangiopancreatography in the elderly. Am J Med Sci 2016;351:84-90.

31. Sugiyama M, Atomi Y. Endoscopic sphincterotomy for bile duct stones in patients 90 years of age and older. Gastrointest Endosc 2000;52:18791 .

32. Lee JK, Lee SH, Kang BK, et al. Is it necessary to insert a nasobiliary drainage tube routinely after endoscopic clearance of the common bile duct in patients with choledocholithiasis-induced cholangitis? A prospective, ran $\neg$ domized trial. Gastrointest Endosc 2010;71:105-10.

33. García-Alonso FJ, de Lucas Gallego M, Bonillo Cambrodón D, et al. Gallstone-related disease in the elderly: is there room for improvement? Dig Dis Sci 2015;60:1770-7.

34. Katsinelos P, Paroutogou G, Kountouras J, et al. Efficacy and safety of therapeutic ERCP in patients 90 years of age and older. Gastrointest Endosc 2006;63:417-23. 